\title{
POSTMENOPAUSAL WOMEN WITH HYPERANDROGENISM: CASE REPORTS OF THREE PATIENTS
}

Andreja Maric, Sonja Medjimurec, Tea Premosa, Dunja Molnar

County Hospital Cakovec, Cakovec, Croatia
ŽUPANIJSKA

BOLNICA

ČAKOVEC

\section{INTRODUCTION}

Androgen excess in women usually is presented as hirsutism and alopecia. Androgens could be expressed from adrenal or ovarian origin.

Female, 58 yrs (Figure 1), presented with postmenopausal hirsutism (FGS 14) and alopecia; DM2, hypertension, hyperlipidemia, obesity (BMI $31.2 \mathrm{~kg} / \mathrm{m}^{2}$ ). Total testosterone was $2.9 \mathrm{nmol} / \mathrm{L}$ and free testosterone 58.2 $\mathrm{pmol} / \mathrm{L}$. MR of abdomen and pelvis revealed enlarged ovaries. Bilateral ovariectomy was performed; PHD: Cellular steroid ovarian tumor. Signs of hyperandrogenism regressed, DM2 is well controlled with metformin. In 3 years follow up there are no signs of hyperandrogenism.

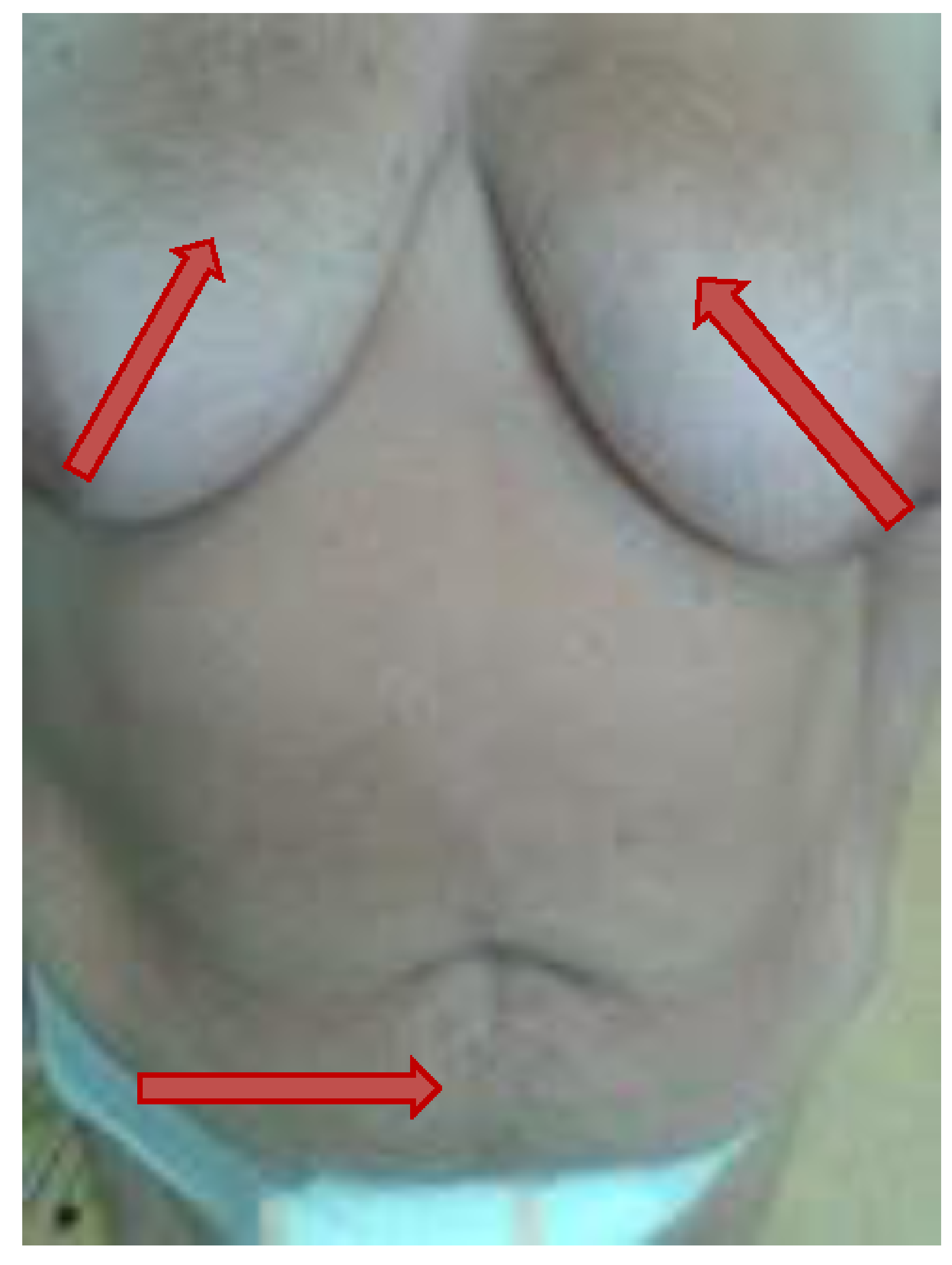

REFERENCES

1)Markopoulos MC, Kassi E, Alexandraki KI, Mastorakos G, Kaltsas G. Hyperandrogenism after menopause. Eur J Endocrinol 2015;172(2):R7991.

2)Souto SB, Baptista PV, Braga DC, Carvalho D. Ovarian Leydig cell tumor in a postmenopausal patient with severe hyperandrogenism. Arq Bras Endocrinol Metabol. 2014;58(1):68-75.

\section{CASE REPORTS}

Female, 57 years (yrs) old, presented with hirsutism (Ferriman Galwey score, FGS 18), weight gain, type 2 diabetes mellitus (DM2), hypertension, hyperlipidemia and obesity (BMI 38.5 $\mathrm{kg} / \mathrm{m}^{2}$ ). Diagnostic evaluation revealed normal prolactin, SHBG, DHEAS, IGF-1, ACTH, TSH, serum cortisol in overnight $1 \mathrm{mg}$ dexamethasone test $(19 \mathrm{nmol} / \mathrm{L})$; total testosterone $(6.0 \mathrm{nmol} / \mathrm{L}$; ref.<2,6), free testosterone $(94.8 \mathrm{pmol} / \mathrm{L}$; ref.<30) and androstendion $(14.1 \mathrm{umol} / \mathrm{L}$; ref.<12) were increased. MRI of abdomen and pelvis showed fatty liver and myoma uteri. Bilateral ovariectomy was performed; PHD: hyperthecosis. Signs of hyperandrogenism regressed.

Postmenopausal woman, $59 \mathrm{yrs}$, presented with perennial DM2, diabetic retinopathy, nephropathy, hypertension, hyperlipidemia, hyperuricemia and obesity (BMI $\left.39.8 \mathrm{~kg} / \mathrm{m}^{2}\right)$. She had weight gain for last $5 \mathrm{yrs}$, with expressed hirsutism (FGS 28). Despite basal-bolus insulin therapy glycemic control is poor $\left(\mathrm{HbA}_{1} \mathrm{c} 9.6 \%\right)$. Diagnostic evaluation revealed normal serum cortisol in overnight $1 \mathrm{mg}$ dexamethasone test $(63.5$ $\mathrm{nmol} / \mathrm{L})$, normal prolactin, TSH, SHBG, DHEAS, IGF-1, ACTH. Total testosterone $(4.1 \mathrm{nmol} / \mathrm{L})$ and free testosterone $(72.9$ $\mathrm{pmol} / \mathrm{L}$ ) were increased. MRI of abdomen and pelvis showed normal adrenal glands, myoma uteri $(25.2 \times 21.7 \times 18 \mathrm{~mm})$, left ovary solid, enlarged $29.3 \times 19.5 \mathrm{~mm}$, and right ovary $14.4 \times 8.6$ $\mathrm{mm}$ in size. Tumor marker CA125 was normal. The patient refused suggested gynecologic surgery, applying only cosmetic treatment.

\section{CONCLUSION}

Resolving the origin of androgen excess is important for adequate treatment. Ovariectomy in described cases resulted in regression of signs of hyperandrogenism. 